\title{
Epidemiology, burden, and policy of chronic obstructive pulmonary disease in South Korea: a narrative review
}

\author{
Eung Gu Lee ${ }^{1}$, Chin Kook Rhee ${ }^{2}$ \\ ${ }^{1}$ Division of Pulmonary and Critical Care Medicine, Department of Internal Medicine, Bucheon St. Mary's Hospital, College of Medicine, The \\ Catholic University of Korea, Seoul, Korea; ${ }^{2}$ Division of Pulmonary and Critical Care Medicine, Department of Internal Medicine, Seoul St. Mary's \\ Hospital, College of Medicine, The Catholic University of Korea, Seoul, Korea \\ Contributions: (I) Conception and design: CK Rhee; (II) Administrative support: CK Rhee; (III) Provision of study materials or patients: CK Rhee; \\ (IV) Collection and assembly of data: EG Lee; (V) Data analysis and interpretation: Both authors; (VI) Manuscript writing: Both authors; (VII) Final \\ approval of manuscript: Both authors. \\ Correspondence to: Chin Kook Rhee, MD, PhD. Division of Pulmonary and Critical Care Medicine, Department of Internal Medicine, Seoul St. Mary's \\ Hospital, College of Medicine, The Catholic University of Korea, 222 Banpo-daero, Seocho-gu, Seoul 06591, Korea. Email: chinkook77@gmail.com.
}

\begin{abstract}
Chronic obstructive pulmonary disease (COPD) is a global health problem and a significant cause of mortality and morbidity worldwide. COPD also occupies a significant and considerable economic burden on individuals and society in South Korea. We investigated the epidemiology and burden of COPD in South Korea and reviewed the policy regarding COPD. In South Korea, a national COPD prevalence survey has been conducted for two decades. The prevalence of COPD has increased with increasing age, particularly among males, and those also with a higher smoking history and with lower income. The total societal cost of COPD increased by 1.85 times between 2004 and 2013. As the use of inhaled medications has increased, the total medical cost per person has increased. The trends of increasing numbers of patients diagnosed with COPD and the total societal costs are expected to continue. There is one universal-healthcoverage system in South Korea. The costs and reimbursement criteria of COPD drugs are established and controlled by the Health Insurance Review and Assessment Service (HIRA). The HIRA has also implemented quality assessment, including evaluating the appropriateness of a COPD diagnosis and treating all COPD patients to reduce the severity of illness and improve the adequacy of medical-care benefits.
\end{abstract}

Keywords: Chronic obstructive pulmonary disease (COPD); epidemiology; burden; policy; South Korea

Submitted Jun 01, 2020. Accepted for publication May 17, 2021.

doi: $10.21037 /$ jtd-20-2100

View this article at: https://dx.doi.org/10.21037/jtd-20-2100

\section{Introduction}

Chronic obstructive pulmonary disease (COPD) is a complex and heterogeneous disease characterized by persistent respiratory symptoms and airflow limitation because of the airway and/or alveolar abnormalities, usually caused by substantial exposure to harmful gas particles (1). COPD is a global health problem and a significant cause of mortality and morbidity worldwide (2). From 1990 to 2015, the prevalence of COPD increased by $44.2 \%$ worldwide (2). In a large-scale study in 2010 using a meta-regression epidemiological model, the number of COPD patients was 384 million, with a global prevalence of $11.7 \%$ (3). According to the Global Burden of Disease (GBD), COPD was the third leading cause of death worldwide in 2010 (4).

COPD occupies a significant and substantial economic burden to individuals and society (5). In 2010, the cost of COPD in the United States was estimated to be approximately \$52 billion, including \$20.4 billion of indirect costs and $\$ 32$ billion of direct healthcare expenditures (5). The three most essential factors in determining the economic costs of COPD are disease severity, frequency of exacerbations, and the presence of comorbidities (6). Because of the significant global burden of disease and 
economic costs and the need for evidence-based guidelines, the Global initiative for chronic Obstructive Lung Disease (GOLD) announced the first consensus report in 2001, which has since been updated (7).

The population of South Korea in 2020 is more than 51 million, and the healthcare system is well-organized. One universal healthcare system and a high-quality epidemiologic survey have been performed for the last two decades. We reviewed the epidemiology, burden, and policy of COPD in South Korea. We searched PubMed for articles in the English language and referenced the Korean Academy of Tuberculosis and Respiratory Diseases Guidelines and data from the National Statistical Office. Relevant papers and articles included those published from 2000 to 2020. This review will be helpful to clinicians worldwide for the management of COPD patients. We present the following article in accordance with the Narrative Review Reporting Checklist (available at https:// dx.doi.org/10.21037/jtd-20-2100).

\section{Epidemiology}

Before establishing the GOLD guidelines, international standards for the diagnosis of COPD were lacking, and diagnostic criteria differed for each survey. In a nationwide survey of COPD in Korea, trained interviewers administered a standardized questionnaire on physiciandiagnosed diseases, socioeconomic factors, health status, and respiratory symptoms (8). Clinical diagnoses and patientreported diagnoses appeared to underestimate disease prevalence. Objective definitions tended to generate higher prevalence estimates than patient-reported diagnoses. For example, pulmonary function test (PFT) criteria derived a higher prevalence estimate than patient-reported COPD using questionnaires (9.2\% versus $4.9 \%$, respectively) (9). This disparity occurs due to the somewhat symptomless nature of the disease, resulting in underdiagnosis by physicians and a lack of awareness of COPD as a disease entity (10). Therefore, PFTs are essential for diagnosing COPD and accurately estimating the prevalence of COPD. The spirometric definition of obstruction using a postbronchodilator forced expiratory volume in 1 second/ forced vital capacity $\left(\mathrm{FEV}_{1} / \mathrm{FVC}\right)$ ratio of $<0.70$ has been consistent since the first GOLD guidelines (7).

In South Korea, the prevalence of COPD was anticipated to be high due to the high rate of cigarette smoking and relatively severe air pollution. Therefore, a nationwide COPD prevalence survey has been performed annually for 20 years. The first systematic, demographically-based epidemiologic study of COPD was conducted as part of the second South Korean National Health and Nutrition Examination Survey (KNHANES II) in 2001, when the prevalence according to the GOLD criteria was $17.2 \%$ among subjects over the age of 45 (8). The prevalence increased with increasing age, particularly among males (males: $25.8 \%$, females: $9.6 \%$ ), those with more than 20 pack-years of smoking, and those with low income (8).

In the KNHANES IV survey conducted in 2008, the prevalence of COPD was $13.4 \%$ among subjects aged $\geq 40$ years (males: $19.4 \%$, females: $7.9 \%$ ) (10). However, the prevalence of COPD and distribution by sex or age group have not changed much since 2008. In 2015, the prevalence of COPD was $13.4 \%$ (males: $21.6 \%$, females: $5.8 \%$ ) (11). The prevalence of COPD in those aged over 65 was $28.1 \%$ (males: $45.5 \%$, females: $13.7 \%$ ) (11). The prevalence was higher with increasing age, being $4.1 \%, 9.7 \%, 21.2 \%$, and $30.6 \%$ in age-stratified groups in their $40 \mathrm{~s}, 50 \mathrm{~s}, 60 \mathrm{~s}$, and 70 s, respectively. As in previous surveys, the prevalence was higher among males and those with low income (11).

In South Korea, the diagnosis rate of COPD is meager. Of the subjects diagnosed with COPD in KNHANES, only $2.4 \%$ reported having been diagnosed with COPD by a physician, and only $2.1 \%$ said having been treated (10). According to Statistics Korea, a central organization for statistics under the Ministry of Strategy and Finance, Korea's population over 40 in 2016 reached 26,853,641, and the known prevalence of COPD was $13.4 \%(10,12)$. Hence and the number of COPD patients was estimated to be approximately $3,598,388$. It was estimated that $2.1 \%$ of these patients, 75,566 patients with COPD, were being treated. According to a study analyzing the cost and prescription of COPD medication in Korea using the HIRA database, the number of patients who received LAMAs in 2011, 2012, and 2013 were 70,346, 76,931, and 78,227, respectively, similar to the above figures (13). Therefore, it was estimated that only $2.1 \%$ of actual COPD patients were being treated.

The number of patients diagnosed with COPD calculated from the Korean National Health Insurance (NHI) database was relatively lower than the worldwide prevalence rate of COPD. This relatively low number of patients with COPD implies that there are likely many patients not yet diagnosed with COPD. They have not received adequate treatment due to a lack of awareness of COPD or mild symptoms (14).

A field survey was conducted in South Korea to increase 


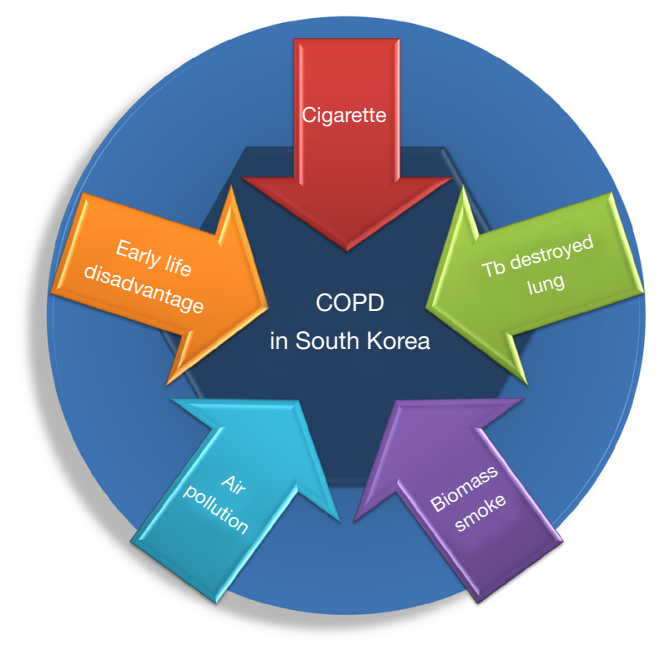

Figure 1 Potential causes of the high prevalence of COPD in South Korea. COPD, chronic obstructive pulmonary disease.

the early diagnosis rate of high-risk COPD patients and improve COPD awareness (15). The study was conducted in males aged over 40 years who were current smokers at enrollment. Handheld spirometry was performed; $\mathrm{FEV}_{1} /$ $\mathrm{FEV}_{6} \leq 0.77$ was considered abnormal, and $30(28.6 \%)$ of 105 participants showed abnormal spirometry results. The majority of smokers underestimate their risk factors associated with smoking compared with nonsmokers (15). The results of this study imply that many COPD patients in South Korea are undiagnosed. It is essential in primary care clinics to find active cases using spirometry. Reports indicate that underdiagnosis of COPD and low utilization of PFTs is a universal phenomenon in Asian countries, including China, Taiwan, Indonesia, the Philippines, and Thailand $(16,17)$.

The prevalence of COPD in Korea is considerably higher than in other countries, and there are potential causes of this high prevalence (Figure 1). Smoking is the most common cause of COPD; among the male patients diagnosed with COPD from the KNHANES IV survey and aged $\geq 40$ years, $41.8 \%$ were current smokers, and $41.2 \%$ were former smokers (10). The smoking rate among males in South Korea was high; in 1995, 66.7\% of adult males were smokers. The higher prevalence of COPD in males $(19.4 \%)$ than females $(7.9 \%)$ is mainly due to the sex difference in the smoking rate (18).

There are also a substantial number of COPD patients in South Korea without a history of cigarette smoking. A previous history of tuberculosis (TB) and subsequent sequelae [TB-destroyed lung (TDL)], biomass-fuel smoke exposure, early life disadvantages, and exposure to pollution can be causes of never-smoker COPD. In South Korea, TB incidence and mortality rates in 2018 were 66 per 100,000 and 4.8 per 100,000 , respectively, higher than in other developed countries $(16,19)$. In the same year, the incidence rates of TB in Japan, the Americas, and Europe were 14, 29 , and 28 per 100,000 , respectively, and the mortality rates were $2.2,2.3$, and 3.0 per 100,000 (19). TB is a risk factor for COPD (20), and TDL can result in airflow obstruction (21). Lung parenchymal injury affects lung compliance, leading to an increased tendency to disrupt the peripheral bronchi and subsequent air trapping. TDL caused by mechanical destruction and stenosis eventually contributes to more fixed airway obstruction (21). One study found that the bronchodilator response (BDR) was significantly lower in patients with TDL than in COPD patients, and COPD appeared even more obstructive ( $\mathrm{FEV}_{1} / \mathrm{FVC}$ ) than TDL (21).

COPD patients with a history of TB developed COPD at an early age, died prematurely, were hospitalized more frequently, and had shorter long-term survival rates than those without a history of TB (22). In addition, COPD patients with a history of TB had lower $\mathrm{FEV}_{1}$ levels and were more hypercapnic (22). In a study conducted in Korea, TB-induced lung parenchymal destruction and airway obstruction were risk factors of COPD in non-smokers (23).

The burden of TDL in South Korea is huge. During 5 years, the total number of TDL patients was 645,031 , and the annual cost per patient was $\$ 1,838$. In all, $68.9 \%$ of 
these patients were prescribed respiratory medications at the cost of $\$ 12$ million during these 5 years (24). Oral systemic bronchodilators (46.5\%) and methylxanthines (35.2\%) were most commonly prescribed, and inhaled corticosteroids (ICSs), long-acting beta-agonists (LABAs), and long-acting muscarinic antagonists (LAMA) were prescribed less at $11.6 \%, 7.5 \%$, and $1.4 \%$, respectively (24).

Many older females in South Korea have been exposed to biomass-fuel smoke in the past. South Korea is now a developed country; however, it was one of the poorest just a few decades ago (25). Biomass smoke exposure is a risk factor for COPD hospitalization and mortality (26,27). The majority of COPD patients exposed to biomass smoke were women and older people. Even with a comparable airflow limitation, they developed more symptoms than COPD patients exposed to tobacco smoke. There was no difference in mortality and exacerbations between COPD patients exposed to biomass smoke and tobacco smoke exposure $(25,28,29)$.

Air pollution also triggers a decline in lung function and increases the risk of developing COPD (30). In the most extensive cross-sectional study of COPD prevalence and the built environment, Sarkar et al. showed that particulate matter $2.5\left(\mathrm{PM}_{2.5}\right)$ exposure and urbanicity were independently associated with higher probability of COPD. In contrast, green exposure had a net protective effect (31).

The level of air pollution in South Korea is high. The average $\mathrm{PM}_{2.5}$ levels are $27.9 \mu \mathrm{g} / \mathrm{m}^{3}$, the highest in the Organization for Economic Co-operation and Development (OECD) (32). This high severity of air pollution was associated with the high prevalence of COPD in South Korea.

Poverty is also a risk factor for COPD (33). Many COPD patients have limited access to healthcare due to poor economic conditions, which increases the risk of disease progression, acute exacerbation, and death from other comorbidities (33). A study was conducted to analyze the association between the prevalence of COPD and socioeconomic status using KNHANES data. Living less than the poverty line was defined as earning a monthly income under the minimum cost of living. Of the 3,223 participants included in this study, 832 (25.8\%) lived under the poverty line. Of these participants, 161 of the 832 people (19.4\%) living under the poverty line, and 223 of the 2,391 people $(9.3 \%)$ living over the poverty line had COPD $(\mathrm{P}<0.001)$ (34). Those living under the poverty line had a lower pulmonary function, lower levels of education, and more comorbidities such as stroke, ischemic heart disease, hypertension, diabetes mellitus, or osteoporosis (34). In multivariable analyses, poverty was significantly associated with COPD even after adjusting for other variables (34).

\section{Burden}

Due to its high prevalence and the potential for severe disability, COPD poses a significant socioeconomic burden (35). In 2012, COPD ranked as the third leading specific cause of total disability-adjusted life years (DALYs) (1,305 per 100,000 population, 6.21\%) in South Korea (36). As the number of older people increases because of the increased average life expectancy, COPD morbidity and the resultant societal costs are also expected to increase gradually.

The NHI covers almost the entire South Korean population. Korean NHI data are a valuable source for analysis of the costs of healthcare utilization in South Korea. Kim et al. used 2004-2013 NHI data and reported the economic burden of COPD. The total societal costs of COPD increased by 1.85 times over the 10 years, from \$238.0 million in 2004 to \$439.9 million in 2013 (14). The total societal costs per patient also increased from $\$ 223.0$ in 2004 to $\$ 309.8$ in 2013. The societal costs of COPD are consist of direct and indirect costs. The direct costs include direct medical costs and direct non-medical costs. The direct medical costs consist of hospitalization, outpatient care, and pharmaceutical costs. The direct nonmedical costs consist of transportation and care-giving. The indirect societal costs include loss of productivity due to morbidity and the value of future loss of income because of premature death (14). The direct societal costs accounted for $58.6-61.0 \%$ of the total societal costs and were higher than the indirect costs, which increased from $\$ 140.2$ million (58.9\%) in 2004 to $\$ 257.7$ million (58.6\%) in 2013. Medical costs accounted for most direct costs, which increased from $\$ 117.1$ million (49.2\% of the total) in 2004 to $\$ 214.3$ million (48.7\% of the total) in 2013. Indirect societal costs also increased, from $\$ 97.8$ million (41.1\%) in 2004 to $\$ 182.2$ million (41.4\%) in 2013 (14).

The Korean Health Insurance Review and Assessment Service (HIRA) database is another excellent source for studying the disease burden of COPD in South Korea. The HIRA database has minute information about the diagnosis, healthcare use, and medication and is thus a definitive source of national epidemiological evaluations (35). Using the HIRA database, Kim et al. (37) reported the costs of COPD in Korea in a multicenter observational study. The direct formal (reimbursed) and informal (non-reimbursed) 
medical costs, evaluated using the COPD population $(n=192,496)$ and based on the HIRA 2009 database, were \$206.9 million and \$44.2 million, respectively. The estimated total (direct and indirect) costs of COPD in 2015 in South Korea were $\$ 1,245.6$ million. Direct medical costs accounted for approximately $20 \%$ of the total costs. The proportions of nursing costs and lost productivity costs were $39 \%$ and $32.7 \%$ of the total.

The HIRA data can provide information on costs according to the type of hospital. A total of 192,496 COPD patients were identified in 2009, of which 185,393 used primary and secondary medical facilities, and 134,722 used tertiary medical facilities (35). Total medical costs per person were $\$ 2,802$ in 2009 . The cost per person was higher for patients attending tertiary medical facilities than those attending primary and secondary facilities $(\$ 2,312 v s$. $\$ 1,230$, respectively) (35). Of note, there was a significant difference in the type of COPD medication between primary and tertiary hospitals. Oral medication was commonly prescribed in primary clinics, while inhalers were prescribed in tertiary care facilities. Costs of medication differed significantly depending on the type of hospital.

The HIRA data are also helpful to analyze the changes in medication use and costs over time. In 2008, LAMA inhalers were used by $26.2 \%(n=48,296)$ of COPD patients in South Korea, and this increased to $37.3 \%(n=78,227)$ in 2013. The cost of LAMAs accounted for the most considerable proportion of the cost of COPD medications. And the total cost of LAMAs increased from $\$ 9,738,800$ in 2008 to $\$ 18,766,800$ in 2013 , a $92.3 \%$ increase over 6 years. In 2008, LABA inhalers were dispensed to only $1.1 \%(n=2,084)$ of COPD patients. In 2013, $6.1 \%$ $(\mathrm{n}=12,843)$ of COPD patients were using LABAs. In 2008, ICS and ICS/LABA inhalers were dispensed to $11.3 \%$ $(n=20,756)$ and $27.4 \%(n=50,500)$ of patients with COPD, respectively, increasing to $11.5 \%(n=26,003)$ and $32.3 \%$ $(\mathrm{n}=72,727)$ in 2012, but then decreasing from 2012 to 2013. The total cost of COPD-related medications increased by $78.2 \%(\$ 20,787,780)$ between 2008 and 2013 , mainly due to increased use of LAMAs and ICS/LABAs, which are more expensive than other COPD medications (13).

The use of inhaled bronchodilators such as LAMAs and LABAs is the basis of pharmacologic treatment in patients with stable COPD to reduce exacerbations and related hospitalizations and improve the effectiveness of pulmonary rehabilitation (1). In fact, admission rates due to COPD were lower in tertiary hospitals and general hospitals, where the rates of prescribing inhaled bronchodilators were high (38). Therefore, the recent increases in medical costs of COPD can be attributed to increased awareness by patients and physicians, together with appropriate diagnosis and treatment. It is speculated that an increase in maintenance use of inhaled bronchodilator treatments will benefit both patients' health and the overall societal economic status.

In South Korea, oral medications such as methylxanthines, systemic beta-agonists, and oral corticosteroids have been widely prescribed. In contrast, inhaled medicines such as LAMAs, LAMA/LABAs, and ICS/LABAs were prescribed to a relatively low proportion of patients with COPD. This has been a significant problem in South Korea and also in other Asian countries (16). Oral beta agonists and methylxanthines can cause a systemic side effects and are not recommended in the treatment of COPD. This discrepancy is important in terms of giving opportunities for better management. Incorrect use of medication can also cause increased additional costs and the burden of exacerbations and adverse effects (13). Fortunately, there has been a gradual improvement in this discrepancy between the COPD guidelines and clinical practice; since 2010, the number of patients prescribed inhalers has increased, while systemic beta-agonist and methylxanthine use has decreased (13).

Pulmonary rehabilitation improves symptoms, quality of life, and physical activities and gives emotional support in the daily life of COPD patients (1). Despite the proven benefits of pulmonary rehabilitation, it has not yet been widely used in clinical practice in Korea (39). As a result of a survey of 28 secondary and tertiary hospitals with 500 beds or more in 2013 , only $25 \%$ of the hospitals implemented pulmonary rehabilitation programs. No hospital conducted a program of more than 6 weeks and more than 3 times a week recommended to maximize the effect of respiratory rehabilitation (39). Considering that only university hospitals participated in the survey, it is estimated that the actual pulmonary rehabilitation is much less performed. Pulmonary rehabilitation has not been activated due to the difficulty of operation due to the low cost of pulmonary rehabilitation, the lack of medical facilities, and the lack of awareness of the medical staff.

The trend of increasing numbers of patients diagnosed with COPD and related direct and indirect societal costs in South Korea are expected to continue. To resolve these problems, further research into appropriate methods to control these costs is warranted. 


\section{Policy}

There is a compulsory and universal health insurance system in South Korea. All COPD medications can be reimbursed by the HIRA, which assesses claims based on diagnostic codes and medical records. GOLD guidelines and Korean COPD clinical practice guidelines provide appropriate guidance for diagnosing and treating patients with COPD. However, there are some gaps between the clinical guidelines and the reimbursement criteria recommended by the HIRA in pharmacologic treatment. In contrast to approaches based on symptom burden and exacerbations in prescribing inhaled medications, reimbursement criteria are predominantly based on $\mathrm{FEV}_{1}$. LAMAs and LAMA/LABAs can only be reimbursed if $\mathrm{FEV}_{1}<80 \%$ predicted, and ICS/ LABAs if $\mathrm{FEV}_{1}$ is $<60 \%$, or if an acute exacerbation occurs more than twice a year. Roflumilast can be reimbursed in chronic bronchitis with either $\mathrm{FEV}_{1}<50 \%$ or $\geq 2$ exacerbations per year despite the use of LAMAs or LABAs.

Many current or former smokers who do not meet the spirometric criteria for COPD have serious respiratory symptoms such as cough, productive cough, or shortness of breath. Recent studies have shown that these patients experience more frequent exacerbations than patients with asymptomatic COPD $(40,41)$. This clinically underestimated population is thought to be in the early phase of lung disease, with the potential to progress. Lowe et al. tried to expand the definition of COPD limited to traditional spirometric obstruction using the COPDgene ${ }^{\circledR}$ study (42). They set criteria for respiratory symptoms, structural abnormality in chest CT, and abnormal spirometric values for patients with more than 10 pack-year smoking history and classified patients into 8 groups (42). The group that satisfies two of these criteria was classified as possible COPD. The group that satisfies three criteria was classified as probable COPD. The group that satisfies all four was classified as definite COPD (42). The odds ratio for change in FEV1 and the hazard ratio for all-cause mortality increased when the groups corresponding to this COPDgene $^{\circledR}$ classification were compared with the group with smoking exposure only (42). When expanded the COPD diagnostic criteria to probable and definite COPD, an additional 1,279 (14.6\%) participants were diagnosed as COPD compared to the traditional spirometric diagnostic criteria. When included possible COPD in the COPD diagnosis, an extra 1,868 (21.4\%) participants were newly diagnosed with COPD (42). Research is ongoing to establish a basis for more intensive management of these patients in the healthcare system; then, the reimbursement criteria will gradually expand.

Disease progression and hospitalizations due to acute exacerbations or comorbidities in patients with COPD can be reduced when outpatients are treated effectively with well-controlled strategies (38). Hospitalization for ambulatory-care-sensitive conditions (ACSCs) is a widely accepted measure of the function of primary care (43). In 2015, the national hospitalization rate for the ACSCs was 180.8 per 10,000 inhabitants. COPD accounted for $3.2 \%$ $(29,469 / 921,210)$ among the ASCSs and was ranked as the ninth most frequent clinical category (43). Therefore, to improve the quality of treatment for patients with COPD, reduce the severity of disease, and improve the adequacy of medical care benefits, the HIRA conducted an evaluation of adequacy based on COPD claims data (38). The first assessment was based on the COPD claims data from May 2014 to April 2015; since then, a nationwide assessment of quality has been performed annually. In terms of assessment criteria, the higher the execution rate of PFTs, percentage of regular visits, and proportion of inhaler prescriptions, the better the outcomes (38). The results of this quality assessment are published on the HIRA website and are available to the public. This allows anyone to see whether patients with COPD are diagnosed adequately through PFTs and prescribed appropriate inhaler medications in the clinical setting (38). The implementation of quality assessment is proving effective at improving COPD management in South Korea, e.g., the rate of PFTs was $36.8 \%$ before and $58.6 \%$ after the assessment (16). The HIRA recommends that COPD patients should visit a clinic regularly. Recently, Park et al. (44) showed that frequent outpatient visits reduced the risk of exacerbations by $45-60 \%$. Frequent visits are associated with PFTs and more use of inhalers.

Under the enactment of the National Health Promotion Act in 1995, various tobacco-control policies, such as smoke-free policies for large buildings and public places, bans on tobacco advertising, smoking cessation media campaigns, graphic warning labels on tobacco products, and increases in tobacco prices, have been actively pursued in Korea (45). In 2015, Korea's National Health Insurance Service started a smoking-cessation support program that included counseling and medication (46). More than 400,000 smokers registered in this program and received support from healthcare providers in 2017. The program consisted of medical counseling consultations and assistance for the cost of administering anti-smoking drugs (46). 


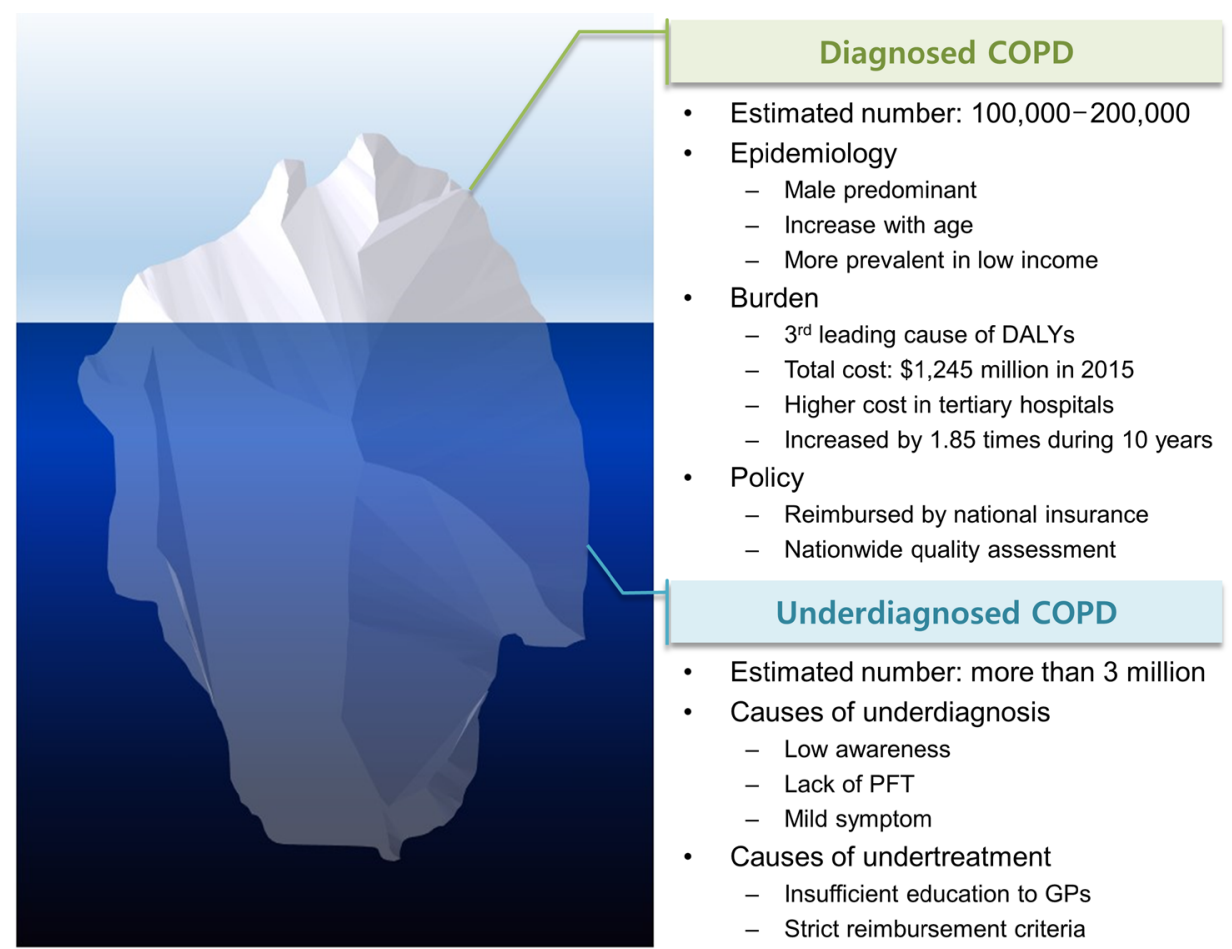

Figure 2 Summary of the current status of COPD in South Korea. DALY, disability-adjusted life years; PFT, pulmonary function test; GP, general practitioner; COPD, chronic obstructive pulmonary disease.

Smoking prevalence in males and females decreased from $71.7 \%$ in 1992 to $39.7 \%$ in 2016 and from $6.5 \%$ in 1992 to $3.3 \%$ in 2016. Between 1992 and 2016, smoking prevalence among males decreased in all age groups (45). However, smoking prevalence among young females in South Korea is increasing. It is necessary to analyze the long-term trends in smoking prevalence in subgroups such as young females and people with low-incomes, whose smoking prevalence has not decreased, and apply the results to tobacco control programs.

Bui et al. proposed six trajectories representing lifetime lung function based on 53 years of spirometry results of 2,689 participants enrolled in the Tasmanian Longitudinal Health Study (TAHS) cohort (47). Three of the six trajectories-early below average, accelerated decline; below average; and persistently low-had a high risk of developing COPD, accounting for $75 \%$ of all COPD cases, and moderate-severe COPD occurred only in these three trajectories. Childhood asthma, bronchitis, pneumonia, allergic rhinitis, parental asthma, and maternal smoking during childhood increased the risk of these three trajectories (47). From a young age, routine spirometry measurements can help to screen for high-risk groups with low lung function. In addition, tobacco-control programs and life-long optimal asthma control should be the basis for clinical and public health policies to reduce the risk of developing COPD.

\section{Conclusions}

The prevalence of COPD in South Korea is high. However, most patients are undiagnosed (Figure 2). Cigarette smoking, previous history of $\mathrm{TB}$, biomass-fuel smoke exposure, early life disadvantages, and air pollution are the major causes of COPD in South Korea (Figure 3). The burden of COPD in South Korea has increased. Although oral medications are still commonly prescribed, the percentage of inhaler use is increasing. All COPD medications are reimbursed based on the HIRA criteria, which are not in accordance with current guidelines. Nationwide quality assessment has improved the management of COPD in South Korea. 


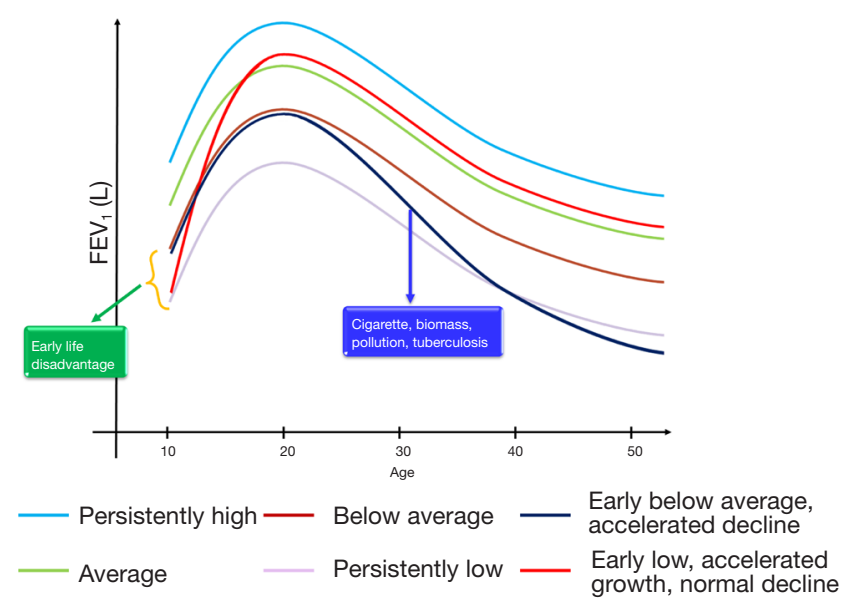

Figure 3 Trajectories of lung function and risk factors in South Korea for early low and accelerated decline.

\section{Acknowledgments}

Funding: None.

\section{Footnotes}

Provenance and Peer Review: This article was commissioned by the Guest Editor (Ki-Suck Jung) for the series "current epidemiology and policies of COPD worldwide" published in Fournal of Thoracic Disease. The article has undergone external peer review.

Reporting Checklist: The authors have completed the Narrative Review Reporting Checklist. Available at https:// dx.doi.org/10.21037/jtd-20-2100

Conflicts of Interest: Both authors have completed the ICMJE uniform disclosure form (available at https:// dx.doi.org/10.21037/jtd-20-2100). The series "current epidemiology and policies of COPD worldwide" was commissioned by the editorial office without any funding or sponsorship. CKR serves as an unpaid editorial board member of Fournal of Thoracic Disease. CKR received consulting/lecture fees from MSD, AstraZeneca, GSK, Novartis, Takeda, Mundipharma, Boehringer-Ingelheim, Teva, Sanofi, and Bayer. The authors have no other conflicts of interest to declare.

Ethical Statement: The authors are accountable for all aspects of the work in ensuring that questions related to the accuracy or integrity of any part of the work are appropriately investigated and resolved.

Open Access Statement: This is an Open Access article distributed in accordance with the Creative Commons Attribution-NonCommercial-NoDerivs 4.0 International License (CC BY-NC-ND 4.0), which permits the noncommercial replication and distribution of the article with the strict proviso that no changes or edits are made and the original work is properly cited (including links to both the formal publication through the relevant DOI and the license). See: https://creativecommons.org/licenses/by-nc-nd/4.0/.

\section{References}

1. Vogelmeier CF, Criner GJ, Martinez FJ, et al. Global Strategy for the Diagnosis, Management, and Prevention of Chronic Obstructive Lung Disease 2017 Report. GOLD Executive Summary. Am J Respir Crit Care Med 2017;195:557-82.

2. Soriano JB, Abajobir AA, Abate KH, et al. Global, regional, and national deaths, prevalence, disabilityadjusted life years, and years lived with disability for chronic obstructive pulmonary disease and asthma, 1990-2015: a systematic analysis for the Global Burden of Disease Study 2015. Lancet Respir Med 2017;5:691-706.

3. Adeloye D, Chua S, Lee C, et al. Global and regional estimates of COPD prevalence: Systematic review and meta-analysis. J Glob Health 2015;5:020415.

4. Lozano R, Naghavi M, Foreman K, et al. Global and regional mortality from 235 causes of death for 20 age groups in 1990 and 2010: a systematic analysis for the Global Burden of Disease Study 2010. Lancet 2012;380:2095-128.

5. Guarascio AJ, Ray SM, Finch CK, et al. The clinical and economic burden of chronic obstructive pulmonary disease in the USA. Clinicoecon Outcomes Res 2013;5:235-45.

6. Mannino DM, Buist AS. Global burden of COPD: risk factors, prevalence, and future trends. Lancet 2007;370:765-73.

7. Mirza S, Clay RD, Koslow MA, et al. COPD Guidelines: A Review of the 2018 GOLD Report. Mayo Clin Proc 2018;93:1488-502.

8. Kim DS, Kim YS, Jung KS, et al. Prevalence of chronic obstructive pulmonary disease in Korea: a populationbased spirometry survey. Am J Respir Crit Care Med 2005;172:842-7.

9. Halbert RJ, Natoli JL, Gano A, et al. Global burden of 
COPD: systematic review and meta-analysis. Eur Respir J 2006;28:523-32.

10. Yoo KH, Kim YS, Sheen SS, et al. Prevalence of chronic obstructive pulmonary disease in Korea: the fourth Korean National Health and Nutrition Examination Survey, 2008. Respirology 2011;16:659-65.

11. Hwang YI, Park YB, Yoo KH. Recent Trends in the Prevalence of Chronic Obstructive Pulmonary Disease in Korea. Tuberc Respir Dis (Seoul) 2017;80:226-9.

12. Population and Housing Census, 2016, Statistics Korea, Republic of Korea. Available online: https://kosis.kr/ statHtml/statHtml.do?orgId=101\&tblId=DT_1IN1603

13. Lee J, Lee JH, Kim JA, et al. Trend of cost and utilization of COPD medication in Korea. Int J Chron Obstruct Pulmon Dis 2017;12:27-33.

14. Kim J, Lee TJ, Kim S, et al. The economic burden of chronic obstructive pulmonary disease from 2004 to 2013. J Med Econ 2016;19:103-10.

15. Hwang YI, Park YB, Yoon HK, et al. Male current smokers have low awareness and optimistic bias about COPD: field survey results about COPD in Korea. Int J Chron Obstruct Pulmon Dis 2019;14:271-7.

16. Rhee CK, Chau NQ, Yunus F, et al. Management of COPD in Asia: A position statement of the Asian Pacific Society of Respirology. Respirology 2019;24:1018-25.

17. Lim S, Lam DC, Muttalif AR, et al. Impact of chronic obstructive pulmonary disease (COPD) in the Asia-Pacific region: the EPIC Asia population-based survey. Asia Pac Fam Med 2015;14:4.

18. Rhee CK. High prevalence of chronic obstructive pulmonary disease in Korea. Korean J Intern Med 2016;31:651-2.

19. World Health Organization. Global tuberculosis report 2019. Available online: https://www.who.int/teams/globaltuberculosis-programme/tb-reports/global-report-2019

20. Global Strategy for the Diagnosis, Management and Prevention of COPD, Global Initiative for Chronic Obstructive Lung Disease (GOLD). 2020. Available online: https://goldcopd.org/wp-content/uploads/2019/11/ GOLD-2020-REPORT-ver1.0wms.pdf

21. Rhee CK, Yoo KH, Lee JH, et al. Clinical characteristics of patients with tuberculosis-destroyed lung. Int J Tuberc Lung Dis 2013;17:67-75.

22. Yakar HI, Gunen H, Pehlivan E, et al. The role of tuberculosis in COPD. Int J Chron Obstruct Pulmon Dis 2017;12:323-9.

23. Myong JP, Yoon HK, Rhee CK, et al. Risk factors for lung function impairment among the general non-smoking
Korean population. Int J Tuberc Lung Dis 2015;19:101926, i-iii.

24. Lee HY, Han DJ, Kim KJ, et al. Clinical characteristics and economic burden of tuberculous-destroyed lung in Korea: a National Health Insurance Service-National Sample Cohort-based study. J Thorac Dis 2019;11:2324-31.

25. Furlow B. Past exposures leave a legacy of pulmonary disease in South Korea. Lancet Respir Med 2018;6:585-6.

26. Sana A, Somda SMA, Meda N, et al. Chronic obstructive pulmonary disease associated with biomass fuel use in women: a systematic review and meta-analysis. BMJ Open Respir Res 2018;5:e000246.

27. Gan WQ, FitzGerald JM, Carlsten C, et al. Associations of ambient air pollution with chronic obstructive pulmonary disease hospitalization and mortality. Am J Respir Crit Care Med 2013;187:721-7.

28. Cho J, Lee CH, Hwang SS, et al. Risk of acute exacerbations in chronic obstructive pulmonary disease associated with biomass smoke compared with tobacco smoke. BMC Pulm Med 2019;19:68.

29. Joo H, Yeo CD, Yoo KH, et al. Comparison of Characteristics of COPD Patients Caused by Biomass Smoke Exposure and Cigarette Smoke Exposure. Am J Respir Crit Care Med 2018:197:A1712.

30. Guo C, Zhang Z, Lau AKH, et al. Effect of long-term exposure to fine particulate matter on lung function decline and risk of chronic obstructive pulmonary disease in Taiwan: a longitudinal, cohort study. Lancet Planet Health 2018;2:e114-25.

31. Sarkar C, Zhang B, Ni M, et al. Environmental correlates of chronic obstructive pulmonary disease in 96779 participants from the UK Biobank: a cross-sectional, observational study. Lancet Planet Health 2019;3:e478-90.

32. Rhee CK. Letter from Korea. Respirology 2018;23:873-4.

33. Grigsby M, Siddharthan T, Chowdhury MA, et al. Socioeconomic status and COPD among low- and middleincome countries. Int J Chron Obstruct Pulmon Dis 2016;11:2497-507.

34. Lee YS, Oh JY, Min KH, et al. The association between living below the relative poverty line and the prevalence of chronic obstructive pulmonary disease. J Thorac Dis 2019;11:427-37.

35. Kim C, Yoo KH, Rhee CK, et al. Health care use and economic burden of patients with diagnosed chronic obstructive pulmonary disease in Korea. Int J Tuberc Lung Dis 2014;18:737-43.

36. Yoon J, Seo H, Oh IH, et al. The Non-Communicable Disease Burden in Korea: Findings from the 2012 Korean 
Burden of Disease Study. J Korean Med Sci 2016;31 Suppl 2:S158-67.

37. Kim C, Kim Y, Yang DW, et al. Direct and Indirect Costs of Chronic Obstructive Pulmonary Disease in Korea. Tuberc Respir Dis (Seoul) 2019;82:27-34.

38. Chung SM, Lee SY. Evaluation of Appropriate Management of Chronic Obstructive Pulmonary Disease in Korea: Based on Health Insurance Review and Assessment Service (HIRA) Claims. Tuberc Respir Dis (Seoul) 2017;80:241-6.

39. Consensus Document on Pulmonary Rehabilitation in Korea, 2015. Seoul: The Korea Academy of Tuberculosis and Respiratory Diseases, 2015.

40. Regan EA, Lynch DA, Curran-Everett D, et al. Clinical and Radiologic Disease in Smokers With Normal Spirometry. JAMA Intern Med 2015;175:1539-49.

41. Woodruff PG, Barr RG, Bleecker E, et al. Clinical Significance of Symptoms in Smokers with Preserved Pulmonary Function. N Engl J Med 2016;374:1811-21.

42. Lowe KE, Regan EA, Anzueto A, et al. COPDGene((R))

Cite this article as: Lee EG, Rhee CK. Epidemiology, burden, and policy of chronic obstructive pulmonary disease in South Korea: a narrative review. J Thorac Dis 2021;13(6):3888-3897. doi: $10.21037 /$ jtd-20-2100
2019: Redefining the Diagnosis of Chronic Obstructive Pulmonary Disease. Chronic Obstr Pulm Dis 2019;6:384-99.

43. Kim AM, Park JH, Yoon TH, et al. Hospitalizations for ambulatory care sensitive conditions as an indicator of access to primary care and excess of bed supply. BMC Health Serv Res 2019;19:259.

44. Park HJ, Byun MK, Kim T, et al. Frequent Outpatient Visits Prevent Exacerbation of Chronic Obstructive Pulmonary Disease. Sci Rep 2020;10:6049.

45. Chang Y, Kang HY, Lim D, et al. Long-term trends in smoking prevalence and its socioeconomic inequalities in Korea, 1992-2016. Int J Equity Health 2019;18:148.

46. YJ P, JK C, ES L, et al. Smoking cessation services provided by the National Health Insurance Service. J Korean Med Assoc 2018;61:157-62.

47. Bui DS, Lodge CJ, Burgess JA, et al. Childhood predictors of lung function trajectories and future COPD risk: a prospective cohort study from the first to the sixth decade of life. Lancet Respir Med 2018;6:535-44. 